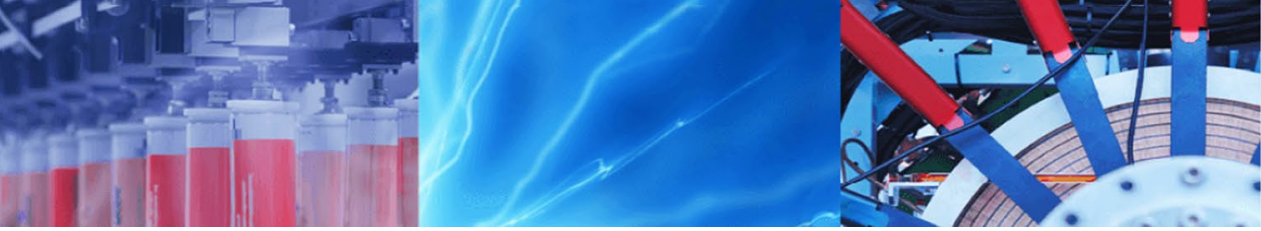

Research Article

\title{
Meteorology and climatology of historical weekly wind and solar power resource droughts over western North America in ERA5
}

\author{
Patrick T. Brown ${ }^{1}$ (1) $\cdot$ David J. Farnham ${ }^{2} \cdot$ Ken Caldeira $^{2}$ \\ Received: 15 June 2021 / Accepted: 7 September 2021 \\ Published online: 27 September 2021 \\ (c) The Author(s) 2021 OPEN
}

\begin{abstract}
Wind and solar electricity generation is projected to expand substantially over the next several decades due both to rapid cost declines as well as regulation designed to achieve climate targets. With increasing reliance on wind and solar generation, future energy systems may be vulnerable to previously underappreciated synoptic-scale variations characterized by low wind and/or surface solar radiation. Here we use western North America as a case study region to investigate the historical meteorology of weekly-scale "droughts" in potential wind power, potential solar power and their compound occurrence. We also investigate the covariability between wind and solar droughts with potential stresses on energy demand due to temperature deviations away human comfort levels. We find that wind power drought weeks tend to occur in late summer and are characterized by a mid-level atmospheric ridge centered over British Columbia and high sea level pressure on the lee side of the Rockies. Solar power drought weeks tend to occur near winter solstice when the seasonal minimum in incoming solar radiation co-occurs with the tendency for mid-level troughs and low pressure systems over the U.S. southwest. Compound wind and solar power drought weeks consist of the aforementioned synoptic pattern associated with wind droughts occurring near winter solstice when the solar resource is at its seasonal minimum. We find that wind drought weeks are associated with high solar power (and vice versa) both seasonally and in terms of synoptic meteorology, which supports the notion that wind and solar power generation can play complementary roles in a diversified energy portfolio at synoptic spatiotemporal scales over western North America.
\end{abstract}

Keywords Electricity grid - Wind power - Solar power - Synoptic meteorology $\cdot$ QG theory $\cdot$ Wind drought $\cdot$ Solar drought · Heat waves · Teleconnections · Extreme weather · Renewable energy · Climatology

\section{Background}

\subsection{Energy system transition}

Global energy consumption by human activities relies largely on fossil fuels that cause global warming and reduce air quality [1]. Thus, governments throughout the world have pursued agreements to decarbonize their economies by implementing policies that encourage an accelerated transition away from fossil fuels [2].

Proposals to decarbonize economies often call for a higher share of total energy consumption to originate from electricity and for that electricity to be generated by non-greenhouse gas emitting technologies [3]. These technologies include wind, solar, nuclear, hydroelectric, and geothermal power, among others. In 2018, wind and

Supplementary Information The online version contains supplementary material available at https://doi.org/10.1007/s42452-02104794-z.

Patrick T. Brown, patrick.brown@sjsu.edu | 'Department of Meteorology and Climate Science, San José State University, San José, CA, USA. ${ }^{2}$ Department of Global Ecology, Carnegie Institution for Science, Stanford, CA, USA.

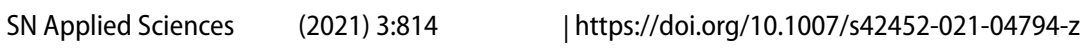


solar power accounted for only $~ 3 \%$ of total global energy consumption [4]. However, over the 2010s, the cost of utility-scale wind and solar power declined by $70 \%$ and $90 \%$ respectively [5] and in an optimistic scenario, the United States Energy Information Administration projects the cost of wind power to decline by a further $60 \%$ and the cost of solar power to decline by a further $75 \%$ by 2050 [6].

These considerations suggest that the global energy infrastructure may be in the early stages of a transition away from electricity generated from mostly fossil fuels and towards electricity generation from near-zero greenhouse gas emissions energy sources, with a substantial fraction generated from wind and solar power. Projections and proposals vary widely, but some call for over $90 \%$ of United States electricity to be generated via wind turbines and solar collectors by the 2030s to 2050s [7-10]. Regardless of their penetration levels by mid-century, wind and solar power should continue to expand in the near-term because, at their current fractional penetration levels, wind and solar power are cost-competitive or cheaper than fossil fuels on a levelized cost of energy (LCOE) basis. However, the total system costs of incorporating wind and solar power scale exponentially as a larger fraction is added to the grid due to their variability $[11,12]$.

\subsection{Challenges associated with wind and solar variability}

Electricity demanded by society must be continuously matched by electricity supplied and thus the primary drawback to wind and solar power is that the resource fueling this electricity is intrinsically variable and does not vary in accordance with demand for energy [13-15].

Energy storage is expected to be capable of redistributing solar power collected during the day to the nighttime hours [16], however, storage costs would need to come down roughly two orders of magnitude in order to allow for near $100 \%$ renewable electricity systems to cope with longer term variability in the wind and solar resource, while keeping system costs near their current levels [11, 17].

Additionally, correlation within a resource across space or correlation between wind and solar resources, represents a challenge to robust, continuous generation of electricity because a reduction in one resource would typically be associated with a simultaneous reduction in the other [12]. Thus, the ability to transmit electricity over large geographic areas is advantageous not only because it is most economically efficient to site wind and solar farms at relatively remote locations where it is climatologically windiest and sunniest, but also because pooling resources over large areas reduces the correlation between and within resources, making the total energy supply less variable [18-23].

\subsection{Purpose of article}

Even renewable energy systems that incorporate long-distance transmission and sufficient energy storage to buffer the daily solar cycle will still be vulnerable to synopticscale weather events (i.e. at the several thousand kilometer spatial scale and several day timescale) characterized by particularly low wind resources, low surface solar radiation and/or large heating or cooling demands. The purpose of this article is to document the meteorology behind historical synoptic-scale reductions in potential wind and solar power energy resources (i.e., "droughts" [24]) as well as their associations with temperature deviations away from human comfort levels that could stimulate electricity demand.

This study is particularly focused on the historical meteorology and climatology of such events (as opposed to their impact on historical or hypothetical energy systems). Thus, we investigate variables averaged over a large domain without regard to particularities of the spatial distribution of wind farms, solar farms or population. This allows us to study the physical relationships between the meteorological variables as a foundation for future work that can address questions specific to particular energy systems.

Another purpose of this article is to investigate whether empirical data conforms to our first order meteorological expectations. Specifically, low pressure systems are simultaneously associated with cloudy conditions (low solar power resource) and windy conditions (high wind power resource) while high pressure systems are simultaneously associated with clear conditions (high solar power resource) and calm conditions (low wind power resource). Thus, a hypothesis that we are testing is that wind droughts are associated with high pressure systems, solar droughts are associated with low pressure systems and the occurrence of a wind or solar drought would make the other kind of drought less likely.

\section{Details of analysis}

When designing the analysis, we were conscious that there is a trade-off between practical usefulness and the illumination of fundamental physical understanding. In this study we strongly emphasize the latter and we do not deal with any practical sociological, technological, or political constraints. Thus, in this study, we take a plot of land roughly the size of an existing electricity grid and document how potential wind power, potential solar power, and temperature deviations away from 65 degrees 
Fahrenheit (i.e., pseudo heating and cooling degree days experienced by land not people) vary and covary at weekly timescales.

\subsection{Spatiotemporal scale of analysis}

For current energy systems, electricity supply and demand mismatches at the hourly timescale have the most societal impact and are the most well studied (e.g., [25]). In this work we study the weekly timescale as we anticipate that this timescale will become relevant in the future as energy storage capacity increases [16]. The weekly timescale also encapsulates the societal cycle in electricity demand associated with the calendar week.

The spatial scale studied here was chosen to be roughly the size of existing large power grids (several million square kilometers). We study an area that approximately encompasses the existing Western Interconnection (WECC) power grid (Fig. 1). This region of western North America (WNA) contains substantial annual mean wind and solar power resources [26-28]. These resources, however, are subject to substantial seasonal and synoptic variability [20, 29-31].
From a meteorological perspective, the weekly timescale and several million square kilometer spatial scale is relevant because these are the scales for which Rossby Waves often manifest at mid latitudes. Rossby Waves would typically traverse our WNA domain in $1 / 2$ to $2 \frac{1}{2}$ days so an individual trough or ridge would typically be a transient phenomenon at the weekly timescale. Nevertheless, the coincidence of two or three such waves of similar character within a week, or a slow-moving cut-off low or blocking high, would cause persistent weather conditions over the domain at the weekly timescale.

This is also a natural spatiotemporal scale to study as it has a long meteorological history in the explanation of temperature and precipitation variability. Such variability is often discussed in the context of preferred states of the atmosphere quantified with teleconnection indices like the Pacific North American Pattern (PNA) [32], Arctic Oscillation (AO) [33], and the North Atlantic Oscillation (NAO) [34], among others. For example, the NOAA Synoptic Discussion typically averages variables over the one week timescale in their retrospective reports on U.S. weather and often discusses these events in the context of the above teleconnection indices [35].

Finally, extreme weather at this spatiotemporal scale has had a demonstrable impact on electricity grids historically.

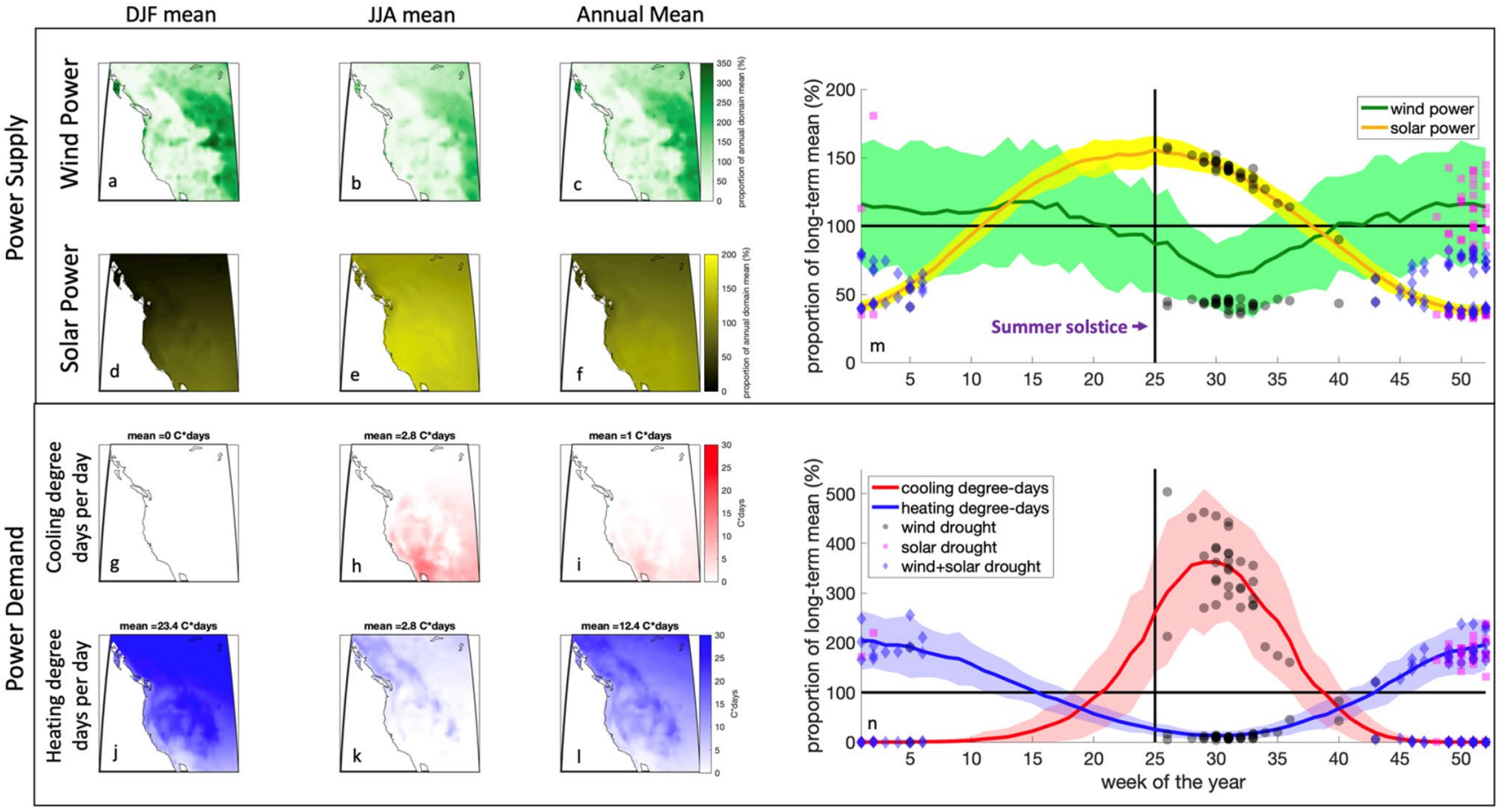

Fig. 1 Climatology of the wind and solar resources and heating and cooling degree days experienced by land. Left) spatial distribution of climatology for different portions of the year. The wind resource considers a wind power curve and the solar resource takes temperature influences on photovoltaic efficiency into account. Both the wind and solar resource are expressed as a proportion of the long term domain mean to emphasize the spatial distribution of the resource rather than the absolute value which depends on technological assumptions. Right) temporal distribution of climatology with 1st percentile drought weeks highlighted 
For example, the rotating electricity outages implemented by the California Independent System Operator Corporation (CAISO) in mid-August 2020 were associated with a thermal ridge over the western half of the United States that corresponded to a strongly positive PNA pattern evident from August 15-21, 2020 [36]. Another pertinent example was the extreme cold event experienced in mid-February 2021 that led to widespread electricity outages in Texas [37]. That event was associated with a persistent trough over the central United States, which corresponds to a strongly negative $\mathrm{AO}$ [35].

The above two instances of electric grid failure were caused mostly by sharp increases in electricity demand for cooling and heating, but both were exacerbated by some reduction in renewable resources and they serve to highlight a spatiotemporal scale at which electricity systems are sensitive. Here we focus on extreme reductions in the wind and solar power resources at roughly the same spatiotemporal scales.

\subsection{Wind and solar droughts}

Henceforth in this study, we refer to a "drought" as a week in which the wind power resource or the solar power resource (or their combination), averaged over the entire week and the entire domain (Fig. 1), is in the first percentile of all weeks considered (from 1950 to 2020). A first percentile week corresponds to a return period of approximately two years. The first percentile is defined with respect to the entire record, not with respect to the mean for that calendar week of the year. We define droughts this way because, from an energy system perspective, the absolute magnitude of the energy resource is what is relevant for meeting electricity demand, not the anomaly relative to the typical seasonal cycle. This is different than the consideration for hydrological droughts in which human and natural systems are thought to already be accustomed and/or adapted to the seasonal cycle and thus it is deviations away from this seasonal cycle that are most important.

The spatial component of the definition of a drought is arbitrary but in this paper we define droughts as lulls in the resource averaged over the entire domain which is roughly the size of the Western Interconnection electricity grid where wind and solar resources might be able to be pooled (Fig. 1).

For compound wind and solar droughts we find the first percentile weeks after both resources have been normalized by their mean over the entire record and summed,

"compound wind and solar droughts" $=1$ st percentile $\left[\frac{\text { wind power }(t)}{\text { mean }(\text { wind power }(t))}+\frac{\text { solar power }(t)}{\text { mean }(\operatorname{solar} p o w e r(t))}\right]$.
In order to illustrate the characteristic atmospheric circulation configuration associated with wind droughts, solar droughts and compound wind and solar droughts, we show composites of many variables over all drought weeks in the dataset (Figs. 3, 4 and 5). The length of our dataset is 71 years (1950-2020 inclusive) which is 3692 weeks. Thus, there are 37 weeks that make up the first percentile. To measure coherence between drought events we stipple the locations where at least $75 \%$ (28 out of 37 ) of the drought weeks agree in the sign of their anomaly (with respect to that calendar week of the year).

\subsection{Variables and data}

All of our analysis is conducted using ERA5 reanalysis data from 1950 to 2020 [38]. ERA5 assimilates a large amount of observations into a dynamical weather model to produce a physically-consistent estimation of the state of the ocean, atmosphere and land surface. We use $1^{\circ} \times 1^{\circ}$ output within the WNA domain (Fig. 1), and $2.5^{\circ} \times 2.5^{\circ}$ for the Northern Hemisphere atmosphere outside of the domain (Figs. 4, 5).

We are primarily interested in the meteorological relationships between the wind resource, the solar resource and temperature. Nevertheless, since this study is motivated by potential future renewable energy systems, we do make some first order adjustments to the resources to better reflect their potential to be converted to electricity. Specifically, we convert hourly wind speed values at $100 \mathrm{~m}$ altitude to hourly wind power at $100 \mathrm{~m}$ via the power curve shown in Fig. S1. For the solar resource, we begin with the hourly downward incident surface solar radiation and we make an adjustment based on that radiation and temperature to account for the attribute that photovoltaic performance is a function of both of these variables [39] (Fig. S2) We do not make further adjustments to either wind or solar power potential because we want the focus to remain on the resources themselves rather than the technology to harvest those resources (which is more subject to uncertainty and change).

ERA5 atmospheric data has a resolution of $31 \mathrm{~km}$ (T639). This resolution is not sufficient to represent mesoscale and boundary layer features that will impact short-timescale variability at the level of particular wind/solar farms. Nevertheless, previous studies have indicated that ERA5 is sufficient to conduct renewable energy analysis at the courser 
resolution that we consider here [19, 40,41]. Additionally, we compare our ERA5-derived variables over specific regions where wind and solar generation data was available from the US Energy Information Administration to confirm that the variability of our reanalysis-inferred solar and wind resources is a reasonable representation of the variability of measured generation in those locations (Figs. S3 and S4).

We also considered daily mean temperature $\left(\left[T_{\min }+T_{\max }\right] / 2\right)$ departures from $65^{\circ} \mathrm{f}\left(18^{\circ} \mathrm{C}\right)$ where positive departures represent cooling degree days (CDDs) and negative departures represent heating degree days (HDDs). We investigate these quantities because they represent the geophysical variables most likely to affect demand-side stress on the energy system $[42,43]$. However, because we want to focus on the physical relationships between wind, surface solar radiation and temperature, regardless of the particularities of the energy system/ population distribution, we do not weigh these CDDs or HDDs by population. Thus, in this paper we discuss CDDs and HDDs experienced by land, not people.

As mentioned above, all values were averaged to the weekly scale prior to subsequent analysis. In order to simplify the analysis and deal with leap years, the first week of each year was defined to begin on January 1 st of that year and 52 weeks were included in each year. This meant that the first 364 days of each year were included in our analysis and the last one or two days of each year were not included.

\section{Results}

We first establish the contextual long-term climatology of the wind power resource, the solar power resource, and heating/cooling degree days (experienced by land) prior to investigating their most extreme weeks.

\subsection{Spatial long-term climatology}

Most of the wind power supply is located on the lee side (i.e., to the east) of the Rocky Mountains in the U.S.'s "wind corridor" (Fig. 1a-c). There is little seasonal spatial shift in the location of the maximum wind supply and instead the stationary pattern intensifies in winter and weakens in summer (c.f. Fig. 1a, b).

The surface solar power resource is concentrated in the southwest corner of the land in the domain but is more homogeneous than the wind power resource because topography exerts a smaller influence on cloud cover than it does on near surface atmospheric flow. Near the summer solstice, the meridional gradient of top-of-atmosphere daily mean incoming solar radiation is very small so most of the spatial variation in surface solar radiation is due to cloud cover (Fig. 1e). Because of this, summer zonal gradients in incident solar radiation can be as large as meridional gradients. Near the winter solstice, on the contrary, the meridional gradient of incident daily mean incoming solar radiation is dominant (Fig. 1d).

The seasonal cycle in HDDs and CDDs is as would be expected. Most of the domain has a long-term daily mean temperature colder than $18{ }^{\circ} \mathrm{C}$ so there are more HDDs than CDDs (c.f. Fig. 1l, i). Seasonally, this affect is most pronounced in the winter when there is nearly zero land experiencing CDDs (Fig. 1g) but substantial HDDs (over 30 HDDs per day over most of the higher latitudes and elevations; Fig. 1j). Even in the summer there are only slightly more CDDs than HDDs when averaged over the domain (c.f. Fig. 1h, k). Despite this, because of the larger use of electricity for cooling than for heating and because of the tendency for people to live in warmer climates, electricity demand over the Western Interconnection tends to peak in the late summer [20]. This pattern of a dual peak in demand (one corresponding to the winter peak in HDDs and one corresponding to the summer peak in (DDs) is observed in actual load data for the United States.

\subsection{Seasonal long-term climatology}

The right side of Fig. 1 shows the mean and standard deviation of the seasonal cycle for the solar power resource, the wind power resource, HDDs and CDDs averaged over the entire WNA domain. All values are expressed as a fraction of their long-term mean value.

The solar power resource runs from $\sim 40 \%$ of its annual mean near the winter solstice to $160 \%$ of its annual mean near the summer solstice (Fig. $1 \mathrm{~m}$ ). Variability in solar power is dominated by the seasonal cycle. This suggests that solar droughts (as defined here using absolute minimum weeks over the entire period) will occur during the weeks near the winter solstice (squares in Fig. $1 \mathrm{~m}, \mathrm{n}$ ).

The seasonal cycle in wind power is slightly anticorrelated with the seasonal cycle in solar power but its phase lags that of solar power by about five weeks (Fig. $1 \mathrm{~m}$ ). The amplitude of the seasonal cycle in wind power is much less than the amplitude of the seasonal cycle in solar power. Wind power supply is about $110 \%$ above its annual mean for much of the cooler portion of the year and it dips to about $60 \%$ of its annual mean in mid to late summer when the Northern Hemisphere meridional temperature gradient, and thus upper-level geostrophic wind, is at an annual minimum. However, wind power variability is dominated by synoptic weather conditions rather than the seasonal cycle. This implies that a wind drought can plausibly occur 
at any time of the year but that they are most-likely in the late summer in July and August (circles in Fig. $1 \mathrm{~m}, \mathrm{n}$ ).

Overall, weekly solar power has $167 \%$ of the variability of weekly wind power and weekly solar variability is dominated by the seasonal cycle ( $99 \%$ of weekly solar variability is linearly explained by the week-of-the-year) while wind power variability is dictated more by atmospheric circulation variability (only $42 \%$ of weekly wind variability is linearly explained by the week-of-the-year).

\subsection{Weekly wind and solar values}

Figure 2 shows the domain mean for each week in the dataset plotted in a two-dimensional wind power and solar power space with CDDs displayed as colors (Fig. S5 shows the corresponding figure with HDDs). Wind droughts are shown as circles with black outlines, solar droughts as squares with black outlines and compound wind and solar droughts as diamonds with black outlines (same as in Fig. $1 \mathrm{~m}, \mathrm{n}$ ).

Wind droughts tended to occur in astronomical summer (Fig. $1 \mathrm{~m}$ and Quadrant II in Fig. 2). During wind droughts, solar power averaged $\sim 135 \%$ of its long-term mean (large dark circle in Fig. 2), with a tendency towards increased CDDs and decreased HDDs.

Solar droughts all occurred around the winter solstice (Fig. $1 \mathrm{~m}$ and Quadrant III and Quadrant IV in Fig. 2). During solar droughts, wind power had a mean of $111 \%$ of its long-term mean (large dark square in Fig. 2), with a tendency towards decreased CDDs and increased HDDs.

Simultaneously considering the proxies for energy supply (Fig. $1 \mathrm{~m}$ and axes of Fig. 2) and energy demand (Fig. 1n and colors of Fig. 2 and Fig. S5), the least stress on the energy system would be experienced in the astronomical spring when both wind and solar power tend to be above their long-term mean and both HDDs and CDDs are near their long-term mean. Conversely, the most stress on the energy system would tend to occur in the astronomical autumn (Quadrant III of Fig. 2), when there tends to be low solar power and still the substantial possibility for low wind power. HDDs are also high at this time (Fig. S5), potentially adding stress on the demand side of an underlying energy system if that system uses electricity for heating.

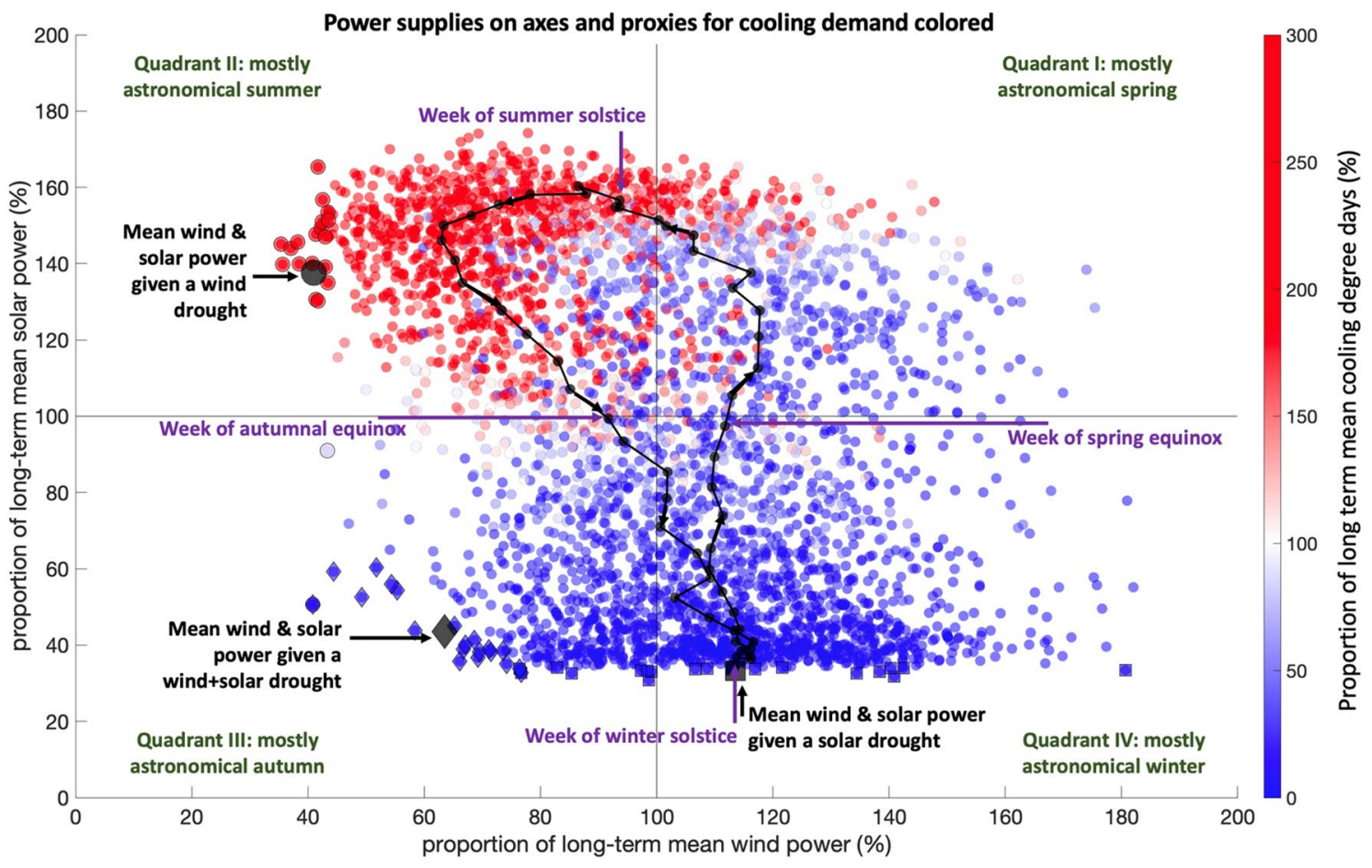

Fig. 2 All weekly values from 1950 to 2020 (average over the western North America domain, Fig. 1) for power supplied by wind and solar resources ( $x$ and $y$ axes respectively) and a proxy for power demanded via cooling degree days (color of dots). The mean seasonal cycle in wind and solar power is shown by the black loop (52 black dots for each week of the year). Drought weeks are indicated with black edge colors with wind droughts represented as circles, solar droughts represented as squares and compound wind and solar droughts represented as diamonds. An animation showing the degree to which there is persistence in time can be seen at https://www.youtube.com/watch?v=xF8u7B5XXzU 
There are 23 weeks in the 71 year time period where CDDs were above their long term mean while both wind and solar resources were below their long term mean (pink and red circles in Quadrant III of Fig. 2). None of these weeks reach the wind/solar drought threshold so we will not focus on them here but they nevertheless indicate potentially large stress on an underlying energy system and may merit study in future research.

Compound wind and solar droughts all occur near the winter solstice (Fig. $1 \mathrm{~m}$ and Quadrant III in Fig. 2). This is because the dominance of the seasonal cycle in solar power confines the compound wind and solar droughts to this time of the year. During compound wind and solar droughts, solar power tends to be $\sim 43 \%$ of its long-term mean and wind power tends to be $\sim 56 \%$ of its long-term mean (dark diamond in Fig. 2), with a tendency towards decreased CDDs and increased HDDs (Fig. S5). Thus heating demand is more of a concern than cooling demand with regard to electricity demand increases exacerbating compound wind and solar droughts.

\subsection{Synoptic meteorology of wind and solar droughts}

Here we assess the first-order, proximate, synopticdynamic mechanisms associated with wind and solar droughts. From this perspective, our expectation is that surface high pressure systems will be associated with subsidence, clear skies (enhanced surface solar radiation) and calm conditions. On the other hand, surface low pressure systems will be associated with ascent, clouds (reduced surface solar radiation) and enhanced wind. As mentioned above, one of our central questions is to see if the empirical data conforms to this first order expectation.

We connect surface high and low pressure systems to dynamic "forcing" aloft by invoking Quasi-Geostrophic (QG) Theory $[44,45]$. QG theory states that under a number of assumptions that are plausible at synoptic spatiotemporal scales, vertical motion in the atmosphere is related to non-geostrophic circulations that restore thermal wind balance: Positive (negative) differential vorticity advection by the geostrophic wind is associated with divergence (convergence) aloft, ascent (subsidence) and low (high) surface pressure. Also, relatively warm (cold) temperature advection by the geostrophic wind implies upward (downward) vertical motion over the lower half of the atmosphere which is associated with surface low (high) pressure. We use a standard meteorological convention of investigating vorticity advection via the relative vorticity at $500 \mathrm{mb}$ (Fig. $5 \mathrm{~d}-\mathrm{f}$ ) and temperature advection at the $700 \mathrm{mb}$ level temperature (Fig. $5 \mathrm{~g}-\mathrm{i}$.).

\subsection{Wind droughts}

Figure 3 shows the average normalized spatial anomalies of wind power, solar power, and temperature variables during drought events. During a typical wind drought, the entire WNA domain tends to experience reduced wind with respect to the mean for that week of the year (spatial average of $43 \%$ of typical wind power, Fig. 3a). During a wind drought, solar power tends to be both above-average seasonally (135\% long-term mean) and slightly above average with respect to the mean for that week of the year (102\%, Fig. 3d). Thus, wind droughts tend to be accompanied by slightly enhanced solar availability. However, wind droughts are consistently associated with slightly less solar power than average over the climatologically sunniest region (indicated by the stippling on the bottom half of the WNA domain in Fig. 3d).

During wind droughts, it tends to be warmer than average to the north where climatological temperatures are below $18^{\circ} \mathrm{C}$ and colder than average to the south where climatological temperatures are above $18^{\circ} \mathrm{C}$ (Fig. 3g). This is indicative of a simultaneous reduction in HDDs and CDDs potentially reducing stress on the demand side of a hypothetical underlying energy system.

Wind droughts tend to be associated with a warm core (dynamic) high over British Columbia flanked by cold core lows on either side (Figs. $4 \mathrm{~d}$ and $5 \mathrm{~g}$ ). This is reminiscent of a positive Pacific North American (PNA) pattern that accentuates the typical meridional deviations in the large-scale atmospheric flow, making it wavier than normal and possibly generating more persistent conditions.

At mid-levels, we see convergence over most of the WNA domain (Fig. 5a) associated with subsidence and high sea level pressure (Fig. $4 \mathrm{~g}$ ). One reason for this is likely the negative vorticity advection on the downstream side of ridge (Fig. $5 \mathrm{~d}$ ) and the negative vorticity advection associated with the left entrance region of a jet streak at $250 \mathrm{mb}$ (Fig. 4a). Additionally, cold air advection over some of the eastern side of the domain promotes subsidence (Fig. $5 \mathrm{~g}$ ). Some positive vorticity advection and divergence is also observed near the southwest U.S. (Fig. 5a, d) which would typically be associated with upward vertical motion and thus is consistent with the region experiencing anomalously cloudy conditions (Fig. 3d).

Sea surface temperature anomalies show a pattern reminiscent of a western Pacific El Niño occurring during an enhanced Aleutian low [46] and a positive phase of the Pacific Decadal Oscillation (PDO, [47-49]) (Fig. 4j). However, the lack of widespread stippling indicates that this is not a necessary condition for a wind drought and that they can easily occur under a diverse set of sea surface temperature patterns (Fig. S13). 


\section{Wind droughts Solar droughts Wind \& Solar droughts}

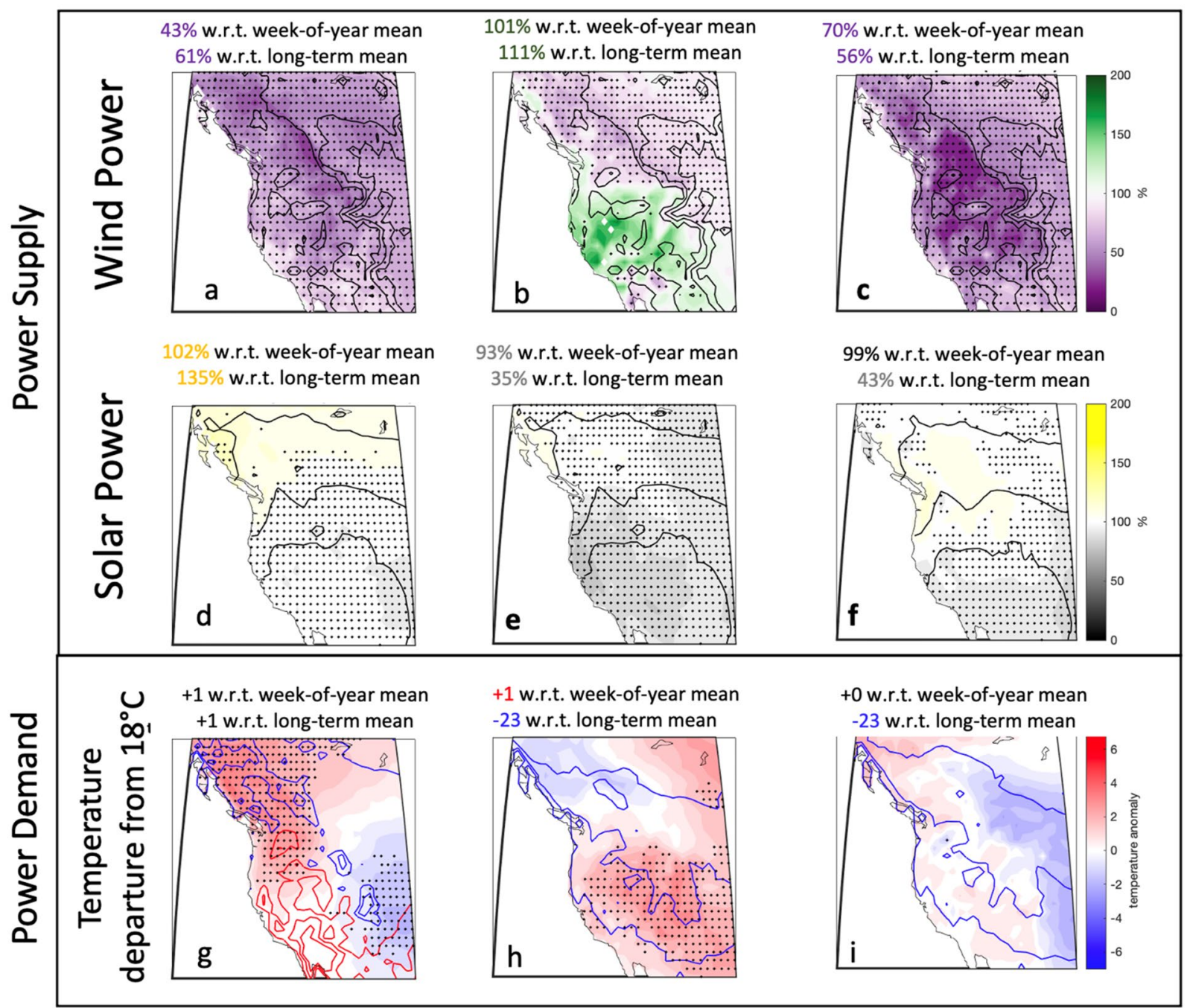

Fig. 3 Composites over the 37 weeks (out of 3692 weeks from 1950 to 2020) with the lowest domain-average wind power $(\mathbf{a}, \mathbf{d}, \mathbf{g})$, solar power $(\mathbf{b}, \mathbf{e}, \mathbf{h})$ and combined wind and solar power $(\mathbf{c}, \mathbf{f}, \mathbf{i})$. The 37 most extreme weeks represent the $\sim 1$ st percentile across the dataset or equivalently, they represent extremes with approximately 2 -year return periods. The colored shading in each panel represents the mean anomaly (either normalized or absolute) with respect to the typical value for that week of the year and the stippling shows where at least 28 of the 37 weeks (>75\%) showed anomalies of the same sign. The mean anomalies with respect to the long-term

\subsection{Solar droughts}

During a typical solar drought, almost the entire WNA domain consistently experiences reduced solar power with respect to the week-of-the-year (spatial average of $93 \%$ of typical values, Fig. 3e). Also, during a solar drought, there tends to be more wind power than average overall ( $111 \%$ of long-term mean, Fig. $3 b$ ) and it tends to be windier than average with respect to the (annual) mean are displayed atop each panel. The contours in panels a-c show the same values as Fig. $1 c$ and the contours in panels $d$-f show the same values as Fig. If which helps illustrate how the anomalies interact with the mean spatial distribution of the resources. The absolute deviation from $18{ }^{\circ} \mathrm{C}\left(65^{\circ} \mathrm{F}\right)$ are contoured in $\mathrm{g}$-i with positive values contoured red and negative values contoured blue. Figures $\mathrm{S6}$-S9 show plots for each individual drought event. Figures S16 and S19 shows the sensitivity of this plot to defining droughts using either the 0.5 th percentile (Fig. S16) or the 2nd percentile (Fig. S19)

\section{SN Applied Sciences}

mean for that week of the year (101\%, Fig. 3b). This is further evidence of an inverse relationship between wind and solar power. This anomalously high wind power is centered over the southwest U.S. but a lack of stippling indicates that the spatial manifestation of this feature is not consistent across solar drought events.

During a typical solar drought, the surface over most of the domain tends to be warmer than average for that week of the year (Fig. 3h). Since the entire domain is typically 

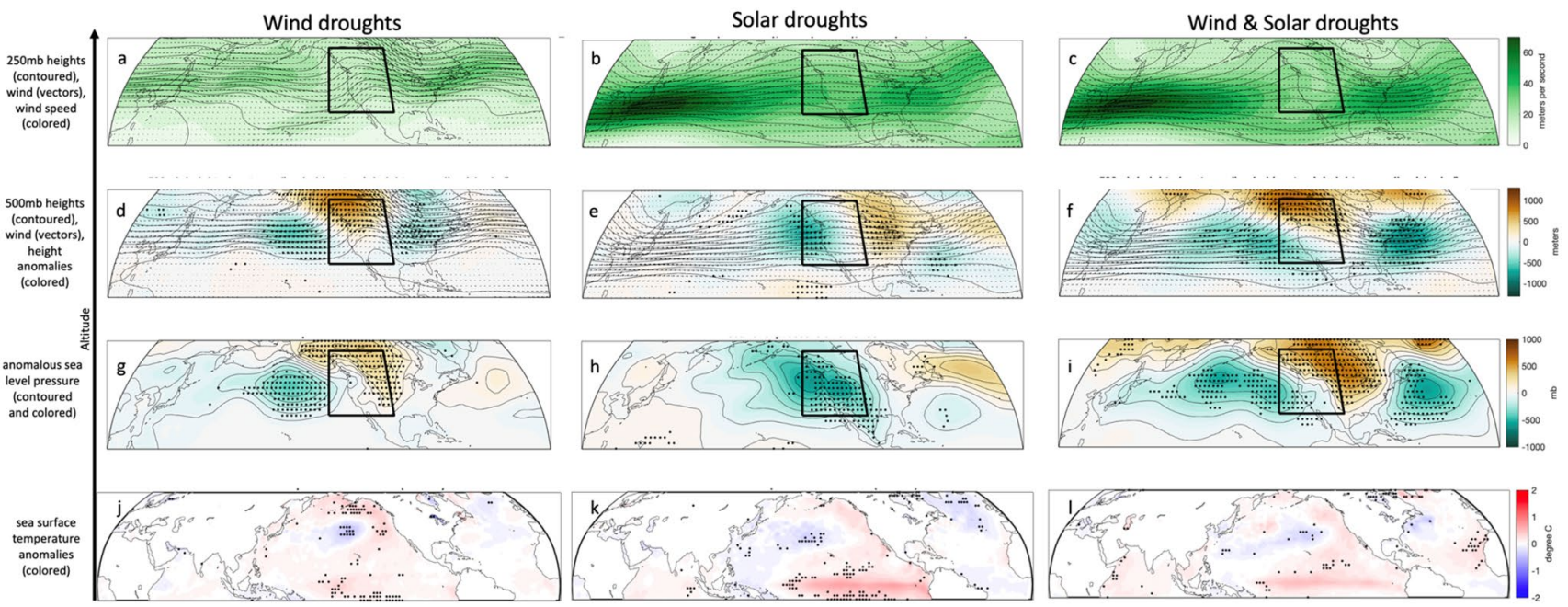

Fig. 4 Composites over the 37 weeks (out of 3692 weeks from 1950 to 2020) with the lowest domain-average wind power $(\mathbf{a}, \mathbf{d}, \mathbf{g}, \mathbf{j})$, solar power (b, e, h, $\mathbf{k})$ and combined wind and solar power $(\mathbf{c}, \mathbf{f}, \mathbf{i}$, I). The 37 most extreme weeks represent the $\sim$ 1st percentile across the dataset or equivalently, they represent extremes with approximately 2-year return periods. The variables displayed are described on the left. All anomalies are defined with respect to the typical value for that week of the year and the stippling shows where at least 28 of the 37 weeks ( $>75 \%$ ) showed anomalies of the same sign. Figures S10-S12 show 500 mb height plots for each individual drought event and Figs. S13-S15 show sea surface temperature anomaly plots for each individual drought event. Figures S17 and S20 shows the sensitivity of this plot to defining droughts using either the 0.5 th percentile (Fig. S17) or the 2nd percentile (Fig. S20)
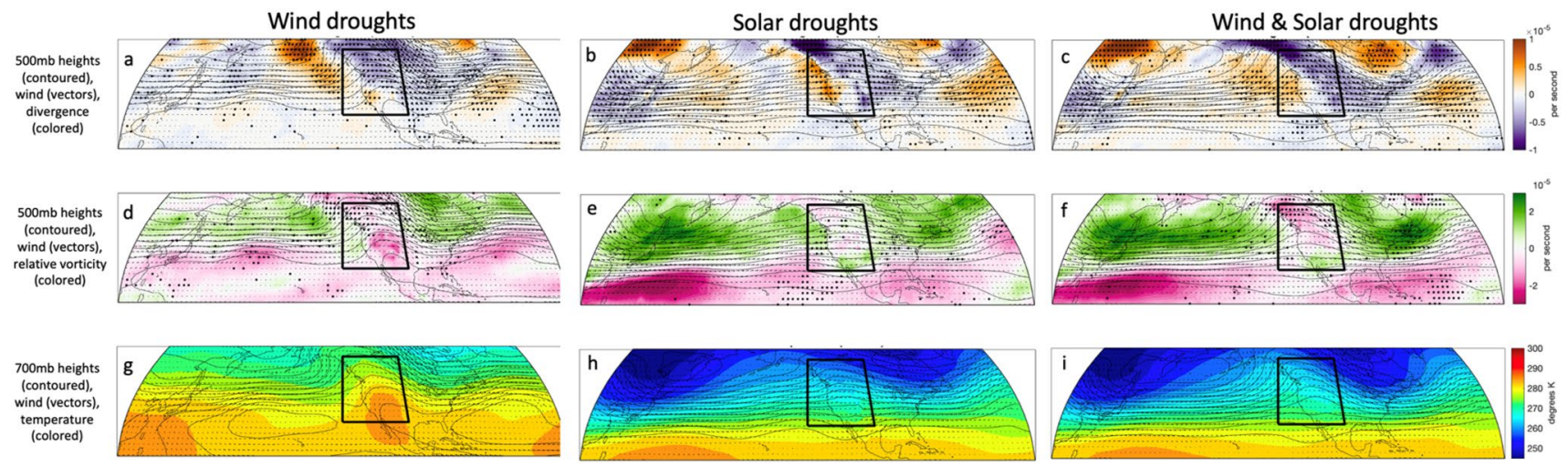

Fig. 5 Composites over the 37 weeks (out of 3692 weeks from 1950 to 2020) with the lowest domain-average wind power (a, d, g), solar power $(\mathbf{b}, \mathbf{e}, \mathbf{h})$ and combined wind and solar power $(\mathbf{c}, \mathbf{f}, \mathbf{i})$. The 37 most extreme weeks represent the $\sim 1$ st percentile across the dataset or equivalently, they represent extremes with approximately 2-year return periods. The variables displayed are described on the left. The stippling shows where at least 28 of the 37 weeks (>75\%) showed values of the same sign. Figures S18 and S21 shows the sensitivity of this plot to defining droughts using either the 0.5 th percentile (Fig. S18) or the 2nd percentile (Fig. S21)

At mid-levels, we see divergence off the west coast of WNA (Fig. 5b), which in turn is associated with ascent, low sea level pressure (Fig. 4h), high winds (Fig. 3b) and cloudier than normal conditions (Fig. 3e). One reason for this is likely the positive shear vorticity advection off the west coast of WNA (Fig. 5e) and the positive vorticity advection associated with the left exit region of a jet streak on the northwest side of the WNA domain at $250 \mathrm{mb}$ (Fig. 4b). Additionally, some slight warm air advection is seen off droughts compared to wind droughts. 
the west coast of WNA which also is associated with ascent (Fig. 5h).

We see some evidence that solar droughts are associated with the positive state of the North Atlantic Oscillation [50,51] (Fig. 4h, k), and are slightly associated with the negative phase of Atlantic Multidecadal Variability ([52] AMV, Fig. 4k) but with little consistency across events (see the diversity of patterns in Fig. S14). There is some evidence of an association with El Niño and this becomes stronger when more extreme solar droughts are considered (using a half percentile threshold, c.f. Fig. 4k with Fig. S17k).

\subsection{Compound wind and solar droughts}

Compound wind and solar drought events tend to be similar in character to wind drought events in terms of their surface manifestation (c.f. the right and left columns of Fig. 3), and their circulations (c.f. the right and left columns of Figs. 3 and 4). There is relatively little atmospheric circulation influence on surface solar radiation (relative to the influence of the seasonal cycle) and thus it is the atmospheric influence on the wind that dictates the occurrence of compound wind and solar droughts.

Compound wind and solar drought events tend to be characterized by warm air advection (Fig. 5i), which would typically be associated with ascent, enhanced winds and storms. However, the negative vorticity advection (Fig. 5f) appears to cancel this effect, resulting in convergence aloft over the climatological windiest region (Fig. 5C).

\section{Discussion and summary}

The purpose of this article was to document the climatology and synoptic meteorology associated with extreme reductions in wind and solar energy resource availability at the weekly timescale over western North America (i.e., wind and solar "droughts").

We found that on the spatiotemporal scale selected (averaged weekly and over all of western North America), solar power varies $2 / 3$ rds more (i.e., $167 \%$ ) than wind power and that solar variability is dominated by the seasonal cycle ( $99 \%$ of weekly-mean solar variability is explained linearly by the week-of-the-year) while wind power variability is dictated more by atmospheric circulation variability (only $42 \%$ of weekly-mean wind variability is explained linearly by the week-of-the-year).

We found that wind droughts tend to occur in late summer when solar power is high, cooling degree days experienced by land tend to be high and heating degree days experienced by land tend to be low. Wind droughts are associated with higher than average solar resources both due to the seasonal cycle and the synoptic weather setup. This supports the notion of added value for energy resource portfolios that include both wind and solar energy [20].

Wind drought events were associated with a thermal mid-level ridge (warm core high) centered over British Columbia near the left entrance region of jet streak. This pattern was also accompanied by mid-level convergence, synoptic scale subsidence and surface high pressure due to negative vorticity advection and cold air advection into the region. This was associated with clear skies and sunnier/warmer conditions to the north of the domain. We found evidence that wind droughts were weakly associated with western Pacific El Niño events during positive PDO but that they appear to emerge predominantly from internal atmospheric variability rather than requiring sea surface temperature anomaly forcing.

We found that solar drought events were confined to near the winter solstice when available wind power tends to be high, CDDs tend to be low and HDDs tend to be high. Solar drought events were associated with a thermal mid-level trough (cold core low) off of the west coast of North America near the left exit region of a jet streak. This pattern was also accompanied by mid-level divergence and synoptic scale ascent due to positive vorticity advection and warm air advection into the region. This was associated with surface low pressure, cloudy, windy and warm conditions in the southwest U.S. There is some evidence that this is associated with a positive North Atlantic Oscillation-like signature, which suggests some potential predictability [53].

We found that compound wind and solar droughts resulted from atmospheric circulation patterns reminiscent of wind droughts but that they occurred in the winter when there was little climatological available solar power. Compound wind and solar droughts occurred seasonally when HDDs were largest and the synoptic circulation associated with the compound drought events exacerbates this to a small degree. This means that the electrification of heating could potentially make these compound wind and solar droughts high stress events on a hypothetical underlying energy system (though this may be simultaneously mitigated by global warming).

Returning to the hypothesis and scientific question posed above, we interpret the results as confirming the hypothesis that wind droughts are typically associated with high pressure systems and solar droughts are typically associated with low pressure systems and thus wind and solar resources should be anti-correlated at synoptic scales. Furthermore, we found that the synoptic-dynamic meteorology of these phenomena was interpretable through Quasi-Geostrophic Theory. This indicates that these droughts are manifestations of 
well-known weather patterns and are not the result of some unexpected or exotic mechanism. This is evidence that wind and solar droughts should be as forecastable as any synoptic weather phenomena on daily to seasonal timescales and it suggests that they should be represented reasonably well by courser resolution climate models.

The dipole and tri-pole like wave patterns in Fig. $4 \mathrm{~d}-\mathrm{f}$ suggest opposite anomalies on the eastern and western sides of North America meaning that below normal wind power (above normal solar power) on the western side of North America would be compensated for by above normal wind power (below normal solar power) on the eastern side of North America. This supports the notion that there is value in moving towards a continental scale "supergrid" connected by high voltage transmission [9]. This may be the case more generally in the sense that electric grids at midlatitudes could greatly benefit from being large enough to encompass the full wavelength of typical Rossby Waves.

Looking forward, mean changes in the wind and solar resource are possible over western North America that could shift the likelihood of wind and solar drought events. Long-term mean incident surface solar radiation is expected to remain roughly steady [54] or perhaps increase slightly [55] due to decreases in relative humidity and clouds over land [56] while long-term mean wind change is uncertain [28] with some studies suggesting a slight increase [55] and others suggesting a slight decrease [57]. We also expect progressively more cooling degree days and less heating degree days [58]. However, these trends in the long-term-mean would not necessarily translate into proportional changes in the statistics of drought events which could be overwhelmed by the particulars of changes in atmospheric circulation like the frequency of atmospheric blocking events [59]. Nevertheless, we found very little evidence for changes in wind and solar droughts historically (Fig. S22).

Overall, this documentary study serves as a prototype for future work that can focus on different locations, different spatiotemporal scales, changes over time, and/or can add more energy system specificity. Ultimately we hope that this may help provide a foundation for the scientific understanding of weather events that will be consequential for renewable energy systems of the future.

Funding This work was supported by a gift to Carnegie Institution for Science from Gates Ventures LLC and by proceeds of the Carnegie Institution endowment.

Data availability The ERA5 data used in this study can be downloaded at https://cds.climate.copernicus.eu/\#!/search?text=ERA5\& type $=$ dataset.
Code availability The code used for this analysis is archived at https:// github.com/ptbrown31/wind_solar_drought.

\section{Declarations}

Conflict of interest The authors declared that they have no conflict of interest.

Open Access This article is licensed under a Creative Commons Attribution 4.0 International License, which permits use, sharing, adaptation, distribution and reproduction in any medium or format, as long as you give appropriate credit to the original author(s) and the source, provide a link to the Creative Commons licence, and indicate if changes were made. The images or other third party material in this article are included in the article's Creative Commons licence, unless indicated otherwise in a credit line to the material. If material is not included in the article's Creative Commons licence and your intended use is not permitted by statutory regulation or exceeds the permitted use, you will need to obtain permission directly from the copyright holder. To view a copy of this licence, visit http://creativecommons. org/licenses/by/4.0/.

\section{References}

1. Oppenheimer M, Petsonk A (2005) Article 2 of the UNFCCC: historical origins. Recent Interpret Clim Change 73:195-226

2. UNFCCC (2015) UNFCCC adoption of the paris agreement. I: Proposal by the president

3. Rogelj J et al (2018) Scenarios towards limiting global mean temperature increase below $1.5^{\circ} \mathrm{C}$. Nat Clim Change 8:325-332

4. BP, Statistical Review of World Energy. 2020. https://www.bp. com/en/global/corporate/energy-economics/statistical-reviewof-world-energy.html

5. Lazard (2020) Levalized cost of energy comparison. https:// www.lazard.com/perspective/levelized-cost-of-energy-level ized-cost-of-storage-and-levelized-cost-of-hydrogen/

6. US EIA, January 2021. Annual energy outlook. https://www.eia. gov/outlooks/aeo/

7. Solving the Climate Crisis (2020) The congressional action plan for a clean energy economy and a healthy resilient and just America. https://climatecrisis.house.gov/report

8. Jacobson MZ et al (2017) $100 \%$ Clean and renewable wind, water, and sunlight all-sector energy roadmaps for 139 countries of the world. Joule 1:108-121

9. Larson E et al (2020) Net-zero America: potential pathways, infrastructure, and impacts. Interim report. Princeton University, Princeton

10. Williams JH, Haley B, Kahrl F, Moore J, Jones AD, Torn MS, McJeon H (2014) Pathways to deep decarbonization in the United States. The U.S. report of the deep decarbonization pathways project of the sustainable development solutions network and the institute for sustainable development and international relations

11. Sepulveda NA et al (2018) The role of firm low-carbon electricity resources in deep decarbonization of power generation. Joule 2:2403-2420

12. Shaner MR et al (2018) Geophysical constraints on the reliability of solar and wind power in the United States. Energy Environ Sci 11:914-925

13. Gowrisankaran $\mathrm{G}$ et al (2016) Intermittency and the value of renewable energy. J Polit Econ 124:1187-1234

14. Trainer T (2012) A critique of Jacobson and Delucchi's proposals for a world renewable energy supply. Energy Policy 44:476-481

15. Ueckerdt $F$ et al (2013) System LCOE: what are the costs of variable renewables? Energy 63:61-75 
16. Albertus $P$ et al (2020) Long-duration electricity storage applications, economics, and technologies. Joule 4:21-32

17. Tong F et al (2020) Effects of deep reductions in energy storage costs on highly reliable wind and solar electricity systems. iScience 23:101484

18. Jurasz J et al (2020) A review on the complementarity of renewable energy sources: concept, metrics, application and future research directions. Sol Energy 195:703-724

19. Jurasz J et al (2021) Complementarity and 'resource droughts' of solar and wind energy in Poland: an ERA5-based analysis. Energies 14:1118

20. Rinaldi KZ et al (2021) Wind and solar resource droughts in california highlight the benefits of long-term storage and integration with the western interconnect. Environ Sci Technol

21. Solomon A et al (2020) Exploiting wind-solar resource complementarity to reduce energy storage need

22. Weschenfelder F et al (2020) A review on the complementarity between grid-connected solar and wind power systems. J Clean Prod 257:120617

23. Yan J et al (2020) Reviews on characteristic of renewables: evaluating the variability and complementarity. Int Trans Electric Energy Syst 30:e12281

24. Rife DK, Cohan DS, Collier JC (2016) A new kind of drought: U.S. record low windiness in 2015. Earthzine. https://earthzine.org/anew-kind-of-drought-u-s-record-low-windiness-in-2015/

25. CAISO (2021) Preliminary root cause analysis. Mid August 2020 Heat Storm. http://www.caiso.com/Documents/PreliminaryRoot-Cause-Analysis-Rotating-Outages-August-2020.pdf

26. Jacobson MZ, Delucchi MA (2011) Providing all global energy with wind, water, and solar power, part i: technologies, energy resources, quantities and areas of infrastructure, and materials. Energy Policy 39:1154-1169

27. MacDonald AE et al (2016) Future cost-competitive electricity systems and their impact on US CO2 emissions. Nat Clim Change 6:526-531

28. Pryor SC, Barthelmie RJ (2011) Assessing climate change impacts on the near-term stability of the wind energy resource over the United States. Proc Natl Acad Sci 108:8167-8171

29. Millstein $D$ et al (2019) Wind energy variability and links to regional and synoptic scale weather. Clim Dyn 52:4891-4906

30. Wang $M$ et al (2018) The future of wind energy in California: future projections with the variable-resolution CESM. Renew Energy 127:242-257

31. Wang M et al (2020) Future projections of wind patterns in California with the variable-resolution CESM: a clustering analysis approach. Clim Dyn 54:2511-2531

32. Wallace JM, Gutzler DS (1981) Teleconnections in the geopotential height field during the northern hemisphere winter. Mon Weather Rev 109:784-812

33. Thompson DWJ, Wallace JM (1998) The Arctic oscillation signature in the wintertime geopotential height and temperature fields. Geophys Res Lett 25:1297-1300

34. Hurrell JW (1995) Decadal trends in the north atlantic oscillation: regional temperatures and precipitation. Science 269:676-679

35. 2021 NOAA National Centers for Environmental Information, State of the Climate: Synoptic Discussion for February 2021. https://www.ncdc.noaa.gov/sotc/synoptic/202101

36. NOAA National Centers for Environmental Information, State of the Climate: Synoptic Discussion for August 2020. 2020. https:// www.ncdc.noaa.gov/sotc/synoptic/202008. 2020b

37. IEA, Severe power cuts in Texas highlight energy security risks related to extreme weather events. IEA, Paris, France, 2021

38. Hersbach $\mathrm{H}$ et al (2020) The ERA5 global reanalysis. Q J R Meteorol Soc 146:1999-2049
39. Bett PE, Thornton HE (2016) The climatological relationships between wind and solar energy supply in Britain. Renew Energy 87:96-110. https://doi.org/10.1016/j.renene.2015.10.006

40. Olauson J (2018) ERA5: The new champion of wind power modelling? Renew Energy 126:322-331

41. Ramirez Camargo L, Schmidt J (2020) Simulation of multi-annual time series of solar photovoltaic power: Is the ERA5-land reanalysis the next big step? Sustain Energy Technol Assessments 42:100829

42. Mourshed M (2016) Climatic parameters for building energy applications: a temporal-geospatial assessment of temperature indicators. Renew Energy 94:55-71

43. Petri Y, Caldeira K (2015) Impacts of global warming on residential heating and cooling degree-days in the United States. Sci Rep 5:12427

44. Carlson TN (1994) Mid latitude weather systems. American Meteorological Society

45. Charney JG (1948) On the scale of atmopsheric motions. Geofysiske Publikasjoner, $\mathrm{p} 17$

46. Alexander MA et al (2002) The atmospheric bridge: the influence of ENSO teleconnections on air-sea interaction over the global oceans. J Clim 15:2205-2231

47. Brown PT et al (2014) Regions of significant influence on unforced global mean surface air temperature variability in climate models. J Geophys Res Atmos 120:480-494

48. Brown PT et al (2017) Change in the magnitude and mechanisms of global temperature variability with warming. Nat Clim Change 7:743

49. Power S et al (1999) Inter-decadal modulation of the impact of ENSO on Australia. Clim Dyn 15:319-324

50. Deser $C$ et al (2010) Sea surface temperature variability: patterns and mechanisms. Ann Rev Mar Sci 2:115-143

51. Hurrell JWKY, Ottersen G, Visbeck M (2003) The north atlantic oscillation: climatic significance and environmental impact. American Geophysical Union

52. Schlesinger ME, Ramankutty N (1994) An oscillation in the global climate system of period 65-70 years. Nature 367:723-726

53. Smith DM et al (2020) North Atlantic climate far more predictable than models imply. Nature 583:796-800

54. Feron $\mathrm{S}$ et al (2021) Climate change extremes and photovoltaic power output. Nat Sustain 4:270-276

55. Gernaat DEHJ et al (2021) Climate change impacts on renewable energy supply. Nat Clim Change 11:119-125

56. Collins $M$, Knutti R, Arblaster J, Dufresne JL, Fichefet T, Friedlingstein P, Gao X, Gutowski WJ, Johns T, Krinner G, Shongwe M, Tebaldi C, Weaver AJ, Wehner M (2013) Long-term climate change: projections, commitments and irreversibility. In: Stocker TF, Qin D, Plattner GK, Tignor M, Allen SK, Boschung J, Nauels A, Xia Y, Bex V, Midgley PM (eds) Climate change 2013: the physical science basis. Contribution of Working Group I to the fifth assessment report of the intergovernmental panel on climate change, Cambridge

57. Karnauskas KB et al (2018) Southward shift of the global wind energy resource under high carbon dioxide emissions. Nat Geosci 11:38-43

58. Li DHW et al (2012) Impact of climate change on energy use in the built environment in different climate zones-a review. Energy 42:103-112

59. Woollings $T$ et al (2018) Blocking and its response to climate change. Curr Clim Change Rep 4:287-300

Publisher's Note Springer Nature remains neutral with regard to jurisdictional claims in published maps and institutional affiliations. 